\title{
Working Under a Clinic-Level Quality Incentive: Primary Care Clinicians' Perceptions
}

Jessica Greene, $\mathrm{PbD}, \mathrm{MPH}$

Ellen T. Kurtzman, MPH, RN ${ }^{1}$

Judith H. Hibbard, DrPH

Valerie Overton, DNP ${ }^{3}$

'School of Nursing, The George Washington University, Washington, DC

${ }^{2}$ Department of Planning, Public Policy, and Management, Health Policy Research Group, University of Oregon

${ }^{3}$ Vice President Quality and Innovation, Fairview Medical Group

\section{$\forall m_{1}$}

MORE ONLINE

www.annfammed.org
Conflicts of interest: Valerie Overton is an employee of Fairview Health Services. The other authors report none.

\section{CORRESPONDING AUTHOR}

Jessica Greene, PhD

School of Nursing

The George Washington University

2030 M Street, NW

Suite 300

Washington, DC 20036

jessgreene@gwu.edu

\begin{abstract}
BACKGROUND A key consideration in designing pay-for-performance programs is determining what entity the incentive should be awarded to-individual clinicians or to groups of clinicians working in teams. Some argue that team-level incentives, in which clinicians who are part of a team receive the same incentive based on the team's performance, are most effective; others argue for the efficacy of clinicianlevel incentives. This study examines primary care clinicians' perceptions of a team-based quality incentive awarded at the clinic level.
\end{abstract}

METHODS This research was conducted with Fairview Health Services, where $40 \%$ of the primary care compensation model was based on clinic-level quality performance. We conducted 48 in-depth interviews to explore clinicians' perceptions of the clinic-level incentive, as well as an online survey of 150 clinicians (response rate $56 \%$ ) to investigate which entity the clinicians would consider optimal to target for quality incentives.

RESULTS Clinicians reported the strengths of the clinic-based quality incentive were quality improvement for the team and less patient "dumping," or shifting patients with poor outcomes to other clinicians. The weaknesses were clinicians' lack of control and colleagues riding the coattails of higher performers. There were mixed reports on the model's impact on team dynamics. Although clinicians reported greater interaction with colleagues, some described an increase in tension. Most clinicians surveyed (73\%) believed that there should be a mix of clinic and individual-level incentives to maintain collaboration and recognize individual performance.

CONCLUSION The study highlights the important advantages and disadvantages of using incentives based upon clinic-level performance. Future research should test whether hybrid incentives that mix group and individual incentives can maintain some of the best elements of each design while mitigating the negative impacts.

Ann Fam Med 2015;13:235-241. doi: 10.1370/afm.1779.

\section{INTRODUCTION}

A s pay-for-performance $(\mathrm{P} 4 \mathrm{P})$ programs have developed in response to calls for aligning health care payment with quality performance, there has been a growing awareness that designing effective P4P programs is a "complex undertaking." ${ }^{1-5}$ One key design decision that must be made is to whom the quality incentive should be awarded. ${ }^{3,4,6-8}$ In the primary care context, the decision is typically whether the incentive should be at the individual level, with each clinician receiving an incentive based on his or her own performance, or at the group or team-level, in which case all clinicians within a clinical team receive the same incentive based on the team's performance.

A number of authors have recommended performance incentives at the team level because of the potential to catalyze system-level changes. ${ }^{1,6,9,10}$ Other arguments supporting team-level incentives include the greater reliability of quality measurement at the group level compared with the individual level, the increasing amount of health care provided by teams rather 
than individuals, the belief that team incentives will better maintain clinicians' intrinsic motivation for providing high-quality care, and that team incentives will bring about greater cooperation among team members. ${ }^{9,11-13}$ Several authors, however, have expressed concern that team-based incentives may result in clinicians getting a free ride on their colleagues' work. ${ }^{1,9,14}$

Recommendations for using individual-level incentives often focus on trying to change behaviors that are under a clinician's control, such as counseling patients on smoking cessation. ${ }^{6,15}$ Mehrotra and colleagues have also argued that individual-level incentives are important for sparking clinician-level quality improvement. ${ }^{16}$ There have been a few calls for mixing approaches and using group-level incentives when team action is essential and using individual incentives when behavior change is dependent on the individual clinician. ${ }^{6,17}$

Reviews of the P4P empirical literature have found that both team and individual incentives can be effective (as well as ineffective). ${ }^{3,4,18-21}$ These reviews typically compare the ratio of studies (or dependent variables) for which quality metrics improved under individual-level incentives to the ratio under team-level incentives. Some authors, such as Eijkenaar and colleagues, have concluded that, "P4P may be more effective when directed at individuals or small teams than when directed at (large) groups." ${ }^{13,4,19,22}$ Others have concluded that it is not possible to determine which has the greater impact. ${ }^{17,21}$

One recent study randomized clinicians to receive individual-level incentives, interdisciplinary team-level incentives, a hybrid combination, or neither (control group) to test the efficacy of the different incentives on care of patients with hypertension. ${ }^{23}$ No differences were observed across the 4 groups in increased use of recommended antihypertensive medications. Patients of clinicians receiving individual-level incentives, however, were better at improving blood pressure control or an appropriate response to uncontrolled blood pressure than were patients of control clinicians. The patients of clinicians receiving hybrid and team-level incentives improved more than the patients of control physicians, but the difference was not statistically significant. Despite using a strong design to test different types of incentives, the findings do not present a clear signal of which entity is the most effective to be given an incentive to improve care.

Our study examined clinicians' experiences with receiving incentives for quality performance at the clinic-level at Fairview Health Services in Minnesota. In 2011, Fairview began implementing an innovative compensation model for primary care clinicians that replaced fee-for-service payment with a largely teambased, quality-focused payment. In the new model,
$40 \%$ of compensation was based upon the clinic-level quality performance, and an additional 10\% was based upon the clinic-level patient's experience.

This mixed methods study examined clinicians' experiences of working under the team-based, qualityfocused compensation model. We explored clinicians' perception of the strengths and weaknesses of having a clinic-level quality performance incentive, and investigated what entity (or entities) the clinicians would reward with incentives to optimize quality improvement.

\section{METHODS}

We conducted in-depth interviews to explore clinicians' perceptions of the benefits and challenges of a clinic-level incentive and an online survey of clinicians to investigate at what level clinicians would consider optimal for performance incentives. The study protocol was approved by the human subjects offices of the University of Oregon, The George Washington University, and the University of Minnesota.

\section{Setting}

This study was conducted in collaboration with Fairview Health Services, a Pioneer Accountable Care Organization that is a large nonprofit health care delivery system in Minnesota with 44 primary care clinics. Fairview's innovative compensation model (which was piloted in 4 clinics in July 2010 and implemented across all clinics in April 2011) shifted primary care clinicians from fee-for-service compensation, which included a potential $\$ 15,000$ annual quality bonus, to a performance-based model in which one-half of the compensation model was based on quality and patient experience. ${ }^{24,25}$ The remaining portion of clinicians' compensation was based upon panel size (10\% team level and $15 \%$ individual level), number of billable and nonbillable patient encounters ( $20 \%$ individual level), and a citizenship component (5\% individual level) that initially was going to be a measure of cost of care..$^{24,25}$ Fairview's model rewarded clinic-based performance rather than individual performance to emphasize the importance of primary care teams in managing population health, strengthen accountability, reduce the likelihood of shifting complex patients to other clinicians $($ "dumping"), and leverage peer pressure.

Teams were made up of all primary care clinicians in a clinic-typically ranging from 5 to 15 physicians, nurse practitioners, and physician assistants (non-primary care clinicians were excluded). Because of the small number of pediatricians, their performance was assessed across all Fairview pediatricians. The quality indicators, from Minnesota Community Measures 
(Supplemental Appendix 1, at http://www.annfammed. org/content/13/3/235/suppl/DC1), included metrics on diabetes, vascular disease, asthma, depression, and cancer screening. The patient experience measure was the Agency for Healthcare Research and Quality Consumer Assessment of Healthcare Providers and Systems Clinician \& Group Survey (CG-CHAPS, https://cahps. ahrq.gov/Surveys-Guidance/CG/index.html).

There were periodic changes to the model, most notably in mid 2012, when in response to a reduction in patient visits, productivity bonuses were added, and specific thresholds for individual relative value unit (RVU) productivity were instituted..$^{25}$

\section{In-depth Interviews}

Two authors, social scientists (J.G and J.H.H.), conducted a total of 48 in-depth interviews. A first round of interviews was conducted approximately 6 months after implementation of the new compensation model $(\mathrm{n}=18)$, and a second round was conducted a year later $(\mathrm{n}=30)$. We recruited clinicians with a wide range of experiences under the model, seeking out those whose incomes increased and decreased. All but 4 interviews were in person, and with 1 exception, all the interviews were audio recorded. Two clinicians were interviewed during both rounds, resulting in a total of 46 clinicians who were interviewed.

The interviews, each lasting approximately $30 \mathrm{~min}$ utes, were based on a semistructured interview protocol that explored clinicians' perceptions of the impact of the compensation model and included specific probes about its influence on quality of care, work environment, relationships with patients, number of patients seen, and cost of care. The protocol did not specifically ask about perceptions of the team aspect of the incentive, but because it was such a key part of the compensation model, almost all respondents raised the issue.

We reviewed the transcribed interviews multiple times to identify key themes from the data, select verbatim text blocks that corresponded to each theme, and detect subthemes. Two members of the research team (J.G. and E.T.K.) independently coded a sample of interview transcripts to compare and reconcile coding. The researchers believed that thematic saturation had been achieved.

\section{Online Survey}

To understand clinicians' experiences more broadly, we conducted an online survey of Fairview's clinicians. The survey questionnaire explored clinicians' experiences working under the compensation model. One item asked what clinicians viewed as "the optimal mix between incentivizing team- and individual-level quality performance in the compensation model." There were 5 response options, ranging from the current model of $100 \%$ team and $0 \%$ individual to $0 \%$ team and $100 \%$ individual.

The questionnaire was sent by e-mail to Fairview's 266 clinicians in the summer of 2013 (2 years and 4 months after the model was adopted), and a total of 150 completed the questionnaire (response rate 56\%). To encourage participation, clinicians who completed the questionnaire could enter a drawing for an iPad (as could in-depth interview participants).

\section{RESULTS}

The characteristics of the study participants are displayed in Table 1. Most of the participants were family practice physicians (57\%) and were women $(60 \%)$, which was similar to the characteristics of the population of all Fairview primary care clinicians. ${ }^{24}$ The in-depth interviewees differed from survey respondents on a number of characteristics (sex, age, specialty), as the purposive sampling for in-depth interviews aimed to reach clinicians who had a broad range of experiences under the model.

\section{Strengths of Clinic-Level Incentives}

Clinicians reported 3 primary strengths of the cliniclevel quality incentive, which fell into 2 key thematic

\begin{tabular}{|c|c|c|}
\hline Characteristics & $\begin{array}{c}\text { In-Depth } \\
\text { Interview } \\
\%\end{array}$ & $\begin{array}{c}\text { Survey } \\
\%\end{array}$ \\
\hline \multicolumn{3}{|l|}{ Type of clinician } \\
\hline Family physician & 50.0 & 57.0 \\
\hline Internist & 10.4 & 8.5 \\
\hline Pediatrician & 16.7 & 13.4 \\
\hline Internist and pediatrician & 6.3 & 7.8 \\
\hline Nurse practitioner & 10.4 & 7.0 \\
\hline Physician assistant & 6.3 & 6.3 \\
\hline \multicolumn{3}{|l|}{ Sex } \\
\hline Male & 56.3 & 40.1 \\
\hline Female & 43.8 & 59.9 \\
\hline \multicolumn{3}{|l|}{ Age, y } \\
\hline$<40$ & 16.7 & 31.9 \\
\hline $40-49$ & 40.0 & 35.5 \\
\hline $50-59$ & 36.6 & 21.3 \\
\hline $60+$ & 6.7 & 11.3 \\
\hline \multicolumn{3}{|l|}{ Years of Fairview employment } \\
\hline$<1$ & 3.3 & 1.4 \\
\hline $1-5$ & 35.5 & 42.3 \\
\hline $6-10$ & 9.7 & 23.9 \\
\hline $11-20$ & 32.3 & 24.7 \\
\hline$\geq 21$ & 19.4 & 7.8 \\
\hline
\end{tabular}


areas-improving quality for the team, and reduced patient dumping because their quality outcomes were poor (Table 2).

Most clinicians mentioned the influence of teambased incentives on their own sense of responsibility to their clinic colleagues. A number of clinicians mentioned trying to improve their own quality to avoid "hurting" the compensation of their team members. As was expressed by a family physician (interviewee No. 38), "Now everyone's looking at my quality, not just if I get a bonus, my quality really impacts my partners' livelihood, so I'd better kick it in gear." An internist (interviewee No. 2) further explained, "I don't wanna be the guy that costs my partners money."

Clinicians also mentioned working harder to achieve higher performance levels for every patient in the clinic - not just their own patients. This sentiment typically came up in the context of seeing another clinician's patient. A family physician (interviewee No. 39) explained, "We're all in this, trying to make patients healthier, so we're working together, and I'll work harder with my partner's patients when I see them."

Several clinicians recognized that by using teamlevel quality incentives, the potential pressure to dump patients was substantially less than it would have been if the clinicians' incentives were based on individual performance. A family physician (interviewee No. 17) explained, "... if they went to just the individual [incentive], some of my diabetics who just haven't been compliant, or continue[d] to smoke,... [could] just get rid of, say I'm not going to see you anymore."

\section{Mixed Strengths and Weaknesses of the Team-Level Incentive}

Clinicians reported that the team-based incentive had both positive and negative impacts on team dynamics. Many clinicians perceived enhanced interaction and collaboration with their peers to be a key benefit of the team incentive. A pediatrician (interviewee No. 44) explained, "I think we are more cohesive now, because we have to exchange our experience as far as [the] quality measures." Another clinician (interviewee No. 16) described that the group incentive, along with transparency of colleagues' performance, pulled people together: "Before it was, like, we're more individual silos, and each doing our own thing, and if somebody else isn't doing as good of a job or doesn't have the quality, you wouldn't necessarily know that because the numbers weren't as out there, but secondarily you didn't feel quite as responsible for them and their practice didn't affect your livelihood as much, whereas now their poor quality affects my income."

Several interviewees also reported the compensation model sparked more learning from colleagues.

\section{Table 2. Key Strengths and Weaknesses of Team-Level Quality Incentives}

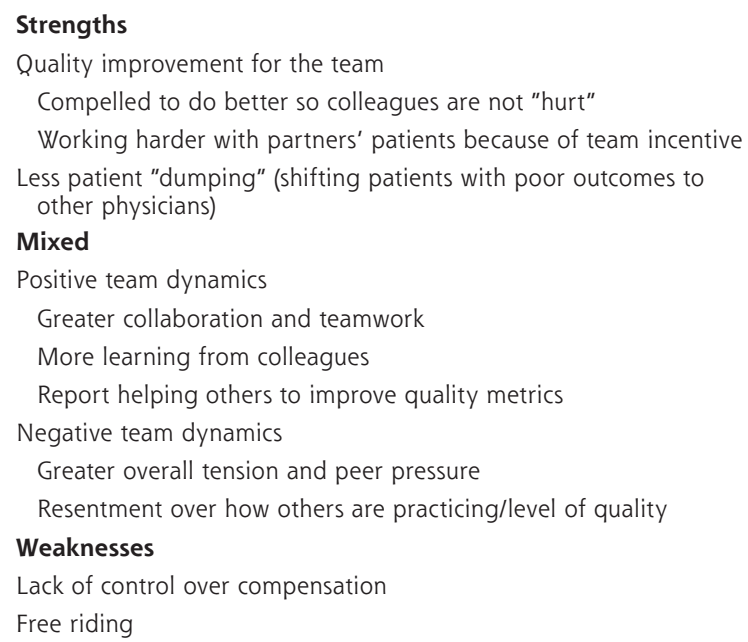

An internist (interviewee No. 2) described reaching out to high performers to learn, asking them, "What are you guys doing that's different than I'm doing?" A physician assistant (interviewee No. 43) also described finding a high-performing colleague, "... who's doing really well-you can lean on that person.... I view it as a [way] to improve myself. If I see my numbers aren't as good, for me it's a motivating thing."

A handful of clinicians reported reaching out to their colleagues with lower quality scores to help them manage their patients better. A family physician (interviewee No. 7) described helping her partner: "I've been on him, but in a nice way, like okay, I ran your list, here's what I did, here's what you could do if you did this, you would get just as much credit as if you had seen 10 patients."

Select interviewees perceived that the team-based incentive led to friction among colleagues, especially among clinicians whose low performance was scrutinized. Although 1 interviewee (No. 12) noted that it was doubtful it would come to "fisticuffs," another (interviewee No. 34) reported instances in which a colleague "would berate people if they weren't at goal." A family physician (interviewee No. 26) explained, "Some people tend to be very independent and resent it. We've lost some people. There's been a shuffling. It doesn't speak to everybody."

On a related issue, several clinicians expressed frustration over not being able to improve how their colleagues' practiced as a means of raising their clinic's performance. One family physician (interviewee No. 33) explained, "Physicians...tend to do things a certain way...it's hard to break out of those habits and molds.... You can encourage them and give sugges- 
tions, but when push comes to shove, they're in the patient's room with their patient, they do their thing... and it's hard for other people to really influence that to a large extent."

\section{Weaknesses of the Team-Level Incentives}

Clinicians perceived 3 primary weaknesses to teamlevel quality incentives that related to lack of control over their compensation and colleagues' free riding (Table 2). Interestingly, a number of the clinicians who described the weaknesses of the team-based model also detailed the model's strengths.

The most frequent objection to the team-based incentive was the clinicians' sense that they lacked control over their own compensation because of the team-based nature of the incentive. A family physician (interviewee No. 7) explained, "My main frustration is the quality numbers that they base my salary on are [the] clinic's quality numbers, not mine. So I can be just a rock star at everything and it doesn't matter at all." An internist (interviewee No. 11), who was highly frustrated with this aspect of the model, said, "I don't have any control over my compensation. I do my job, and I don't get paid for my job."

Among the pediatricians, whose incentives were based on all Fairview pediatricians' performance, the lack of influence over their colleagues was particularly frustrating. Several, in fact, mentioned not knowing some of their colleagues across the system, yet these colleagues' performance influenced their salary.

Some clinicians perceived the team-based incentive to be unfair, because some low performers did not feel they needed to improve their own performance. A family physician (interviewee No. 45) explained, "My colleagues who... don't have numbers as good as mine, ride on my coattails because I up the average." An internist (interviewee No. 29) elaborated, "... since it's the clinic quality score that determines your pay, if your numbers are higher, you're being punished two ways. Number 1, the clinic average brings you down [and] your pay decreases. Number 2, you bring those who have poor quality numbers up, so they're being paid more, and they don't have any incentive to improve. This system is benefitting them without doing extra work."

\section{The Optimal Mix-Team vs Individual Incentive}

When surveyed about the optimal mix between teamlevel and individual-level quality performance incentives, almost three-quarters (73\%) of respondents believed that there should be a mix between team- and individual-level incentives (not shown) to balance inspiring collaboration and recognizing individual performance. One-third (34\%) favored an even split-50\% team-based and $50 \%$ individual-based incentives. As one respondent reported: "This would allow individuals who work hard at quality to be rewarded, but still encourage teamwork...."

There was only a small minority $(15 \%)$ who favored an exclusively team-based incentive, which reflects the model implemented by Fairview. One clinician explained, "Making it more individual would destroy collegiality. It would make each clinic competitive and an unpleasant place to work." Fewer than 7\% favored an entirely individual-based quality incentive. Rather than endorsing an individual-level incentive, these clinicians were harsh in their criticism of team-based incentives. A clinician explained, "I cannot change my colleagues' habits at all. It has not happened in the 5 or more years we have been working on quality, so it is not going to happen now. Unless they are losing pay, some are never going to work aggressively on quality."

\section{DISCUSSION}

This study examined clinicians' experiences working under a team-based, quality-focused compensation model. The clinicians reported some key benefits of team-level incentives, including clinicians' improved quality performance as it related to feeling a sense of responsibility to the team and greater collaboration with colleagues. The team-level incentive created substantial frustration among many clinicians, however, including many of those who reported benefits of the model. The frustration was principally based upon clinicians feeling they had little control over their own compensation and that some colleagues were riding on their coattails.

After almost 2.5 years of working under the teambased, quality-focused compensation model, only a small minority (15\%) would base quality incentives entirely at the team level-effectively rejecting the incentive approach under which they were working. Fewer still (7\%) were interested in basing quality incentives exclusively at the individual level. They feared increases in patient dumping and decreased collegiality. Interestingly, almost three-quarters of clinicians $(73 \%)$ thought that a hybrid model, mixing both individual-level and team-level incentives would be best-because of the potential to maintain the strengths of each model while mitigating their weaknesses.

There has been little research on using hybrid incentive models in health care. One important exception found that quality of care by clinicians randomized to hybrid incentive models improved less (though not significantly less) than it did by those working under individual-level incentives. ${ }^{23}$ Conversely, clini- 
cians' care quality improved more under the hybrid model (though not significantly more) than it did for those working under a team-level incentive. Similarly, a laboratory study in the management literature found hybrid incentives resulted in harder work than team incentives, but they worked less cooperatively. ${ }^{13}$ Clearly more research is needed to explore the efficacy of hybrid models as well as clinicians' experiences working under them.

The results of this study should be interpreted in light of its limitations. The research was conducted in a single delivery system where one-half of clinicians' compensation was based upon team-level quality and patients' experience. The results may not be generalizable to $\mathrm{P} 4 \mathrm{P}$ programs with smaller portions of compensation at stake or where teams are multidisciplinary. The large portion of compensation at stake in this study, however, likely highlighted the advantages and disadvantages of the team-based model. The data were collected at 3 different times, and although results were largely consistent, it is unclear how the timing may have influenced clinicians' perspectives. Finally, the clinicians never had an individual-level quality incentive at Fairview with which to compare the clinic-level incentive, though they were accustomed to individual-level productivity incentives. Despite these limitations, the results are largely consistent with the strengths and weaknesses of group-level incentives described in the management literature. 13,26,27

This study highlights the complexity of designing financial incentive programs. Clinic-level incentives resulted in clinicians coming together to improve quality, but many reported becoming frustrated by the lack of control over their salary. Individual-level incentives, however, were thought by many to "destroy collegiality" and encourage patient dumping. These concerns suggest that those contemplating delivery systems with either type of incentive need to consider ways to address the model's limitations. For instance, delivery systems with individual-level quality incentives should include ways to strengthen teamwork. Future evaluations are needed to test approaches to addressing the weaknesses of the 2 models, as well as assessing whether hybrid models maintain the strengths of each model while mitigating their weaknesses.

To read or post commentaries in response to this article, see it online at http://www.annfammed.org/content/13/3/235.

Key words: quality improvement; physician incentive plans

Submitted August 5, 2014; submitted, revised, January 28, 2015; accepted February 11, 2015.

Funding support: This research was supported by The Commonwealth Fund, a national, private foundation based in New York City that sup- ports independent research on health care issues and makes grants to improve health care practice and policy.

Disclaimer: The views presented here are those of the authors and not necessarily those of The Commonwealth Fund, its directors, officers, or staff.

Acknowledgments: We would like to thank the primary care clinicians who participated in the study for sharing their experiences and stories with the research team and to Fairview Health Services for their openness to research.

Supplementary materials: Available at http://www.AnnFamMed. org/content/13/3/235/suppl/DC1/.

\section{References}

1. Eijkenaar F. Key issues in the design of pay for performance programs. Eur J Health Econ. 2013;14(1):117-131.

2. Scott A, Sivey P, Ait Ouakrim D, et al. The effect of financial incentives on the quality of health care provided by primary care physicians. Cochrane Database Syst Rev. 2011; Sep 7;(9):CD008451.

3. Petersen LA, Woodard LD, Urech T, Daw C, Sookanan S. Does pay-for-performance improve the quality of health care? Ann Intern Med. 2006;145(4):265-272. http://www.annals.org/cgi/content/ abstract/145/4/265.

4. Eijkenaar F, Emmert M, Scheppach M, Schöffski O. Effects of pay for performance in health care: a systematic review of systematic reviews. Health Policy. 2013;110(2-3):115-130.

5. McDonald R, Roland M. Pay for performance in primary care in England and California: comparison of unintended consequences. Ann Fam Med. 2009;7(2):121-127.

6. Rosenthal MB, Dudley RA. Pay-for-performance: will the latest payment trend improve care? JAMA. 2007;297(7):740-744.

7. Mehrotra A, Sorbero MES, Damberg CL. Using the lessons of behavioral economics to design more effective pay-for-performance programs. Am J Manag Care. 2010;16(7):497-503.

8. Dudley RA, Frolich A, Robinowitz DL, et al. Strategies To Support Quality-based Purchasing: A Review of the Evidence. Published 2004. http://www.ncbi.nlm.nih.gov/books/NBK43997/pdf/TOC.pdf.

9. Conrad DA, Perry L. Quality-based financial incentives in health care: can we improve quality by paying for it? Annu Rev Public Health. 2009;30:357-371.

10. Town R, Wholey DR, Kralewski J, Dowd B. Assessing the influence of incentives on physicians and medical groups. Med Care Res Rev. 2004;61(3)(Suppl):80S-118S.

11. Trisolini M. Theoretical perspectives on pay for performance. In: Cromwell J, Trisolini MG, Pope GC, Mitchell JB, Greenwald LM, eds. Pay for Performance in Health Care: Methods and Approaches. Research Triange Park, NC: RTI Press; 2011:77-98. Published March 2011. https://www.rti.org/pubs/bk-0002-1103-mitchell.pdf.

12. Wynia MK. The risks of rewards in health care: how pay-forperformance could threaten, or bolster, medical professionalism. J Gen Intern Med. 2009;24(7):884-887. http://dx.doi.org/10.1007/ s11606-009-0984-y.

13. Barnes CM, Hollenbeck JR, Jundt DK, DeRue DS, Harmon SJ. Mixing Individual incentives and group incentives: best of both worlds or social dilemma? J Manage. 2010;37(6):1611-1635.

14. Town $R$, Kane $R$, Johnson $P$, Butler $M$. Economic incentives and physicians' delivery of preventive care: a systematic review. Am J Prev Med. 2005;28(2):234-240.

15. Gaynor M, Rebitzer JB, Taylor LJ. Physician incentives in health maintenance organizations. J Polit Econ. 2004;112(4):915-931. 
16. Mehrotra A, Pearson SD, Coltin KL, et al. The response of physician groups to P4P incentives. Am J Manag Care. 2007;13(5):249-255.

17. Campbell SM, Scott A, Parker RM, et al. Implementing pay-forperformance in Australian primary care: lessons from the United Kingdom and the United States. Med J Aust. 2010;193(7):408-411.

18. Van Herck P, De Smedt D, Annemans L, Remmen R, Rosenthal $M B$, Sermeus W. Systematic review: Effects, design choices, and context of pay-for-performance in health care. BMC Health Serv Res. 2010;10:247. http://www.biomedcentral.com/1472-6963/10/247.

19. Frølich A, Talavera JA, Broadhead P, Dudley RA. A behavioral model of clinician responses to incentives to improve quality. Health Policy. 2007;80(1):179-193.

20. Houle SKD, McAlister FA, Jackevicius CA, Chuck AW, Tsuyuki RT. Does performance-based remuneration for individual health care practitioners affect patient care?: A systematic review. Ann Intern Med. 2012;157(12):889-899.

21. Emmert M, Eijkenaar F, Kemter H, Esslinger AS, Schöffski O. Economic evaluation of pay-for-performance in health care: a systematic review. Eur J Health Econ. 2012;13(6):755-767.
22. Conrad DA, Grembowski D, Perry L, Maynard C, Rodriguez H, Martin D. Paying physician group practices for quality: A statewide quasi-experiment. Health Care (Don Mills). 2013;1(3-4):108-116.

23. Petersen LA, Simpson K, Pietz K, et al. Effects of individual physician-level and practice-level financial incentives on hypertension care: a randomized trial. JAMA. 2013;310(10):1042-1050.

24. Greene J, Hibbard JH, Overton V. A case study of a team-based, quality-focused compensation model for primary care providers. Med Care Res Rev. 2014;71(3):207-223.

25. Greene J, Hibbard J, Overton V. Large performance incentives had the greatest impact on providers whose quality metrics were lowest at baseline. Health Affairs. 2015;34 (4): 73-680.

26. Beersma B, Hollenbeck JR, Humphrey SE, Moon H, Conlon DE, Ilgen DR. Cooperation, competition, and team performance: toward a contingency approach. Acad Manag J. 2003;46(5):572-590.

27. Wageman R. Interdependence and Group Effectiveness. Adm Sci Quarterly. 1995;40(1):145-180. 